\title{
Diffuse axonal injury in early infancy
}

\author{
G H VOWLES, C L SCHOLTZ, J M CAMERON*
}

From the Departments of Morbid Anatomy and *Forensic Medicine, The London Hospital

SUMMARY Diffuse axonal injury typified by retraction balls and axonal swellings was identified in the brains of a series of infants, 5 months old and younger, who had suffered closed head injuries. These axonal discontinuities were shown by using Nauomenko and Feigin's silver method, which is particularly useful for showing fine axons such as those found in the developing brain.

Diffuse axonal injury in early infancy may occur in the same way as that described in adults. The low incidence of intracerebral haematomata suggests that recurrent trauma to the head from a combination of direct contact and shaking results in axonal damage to the poorly myelinated axons and that blood vessels are rarely damaged.

Closed head injury in early infancy $(5$ months of age and younger) produces focal lesions, contusional tears, and diffuse astrocytic reaction. ${ }^{12}$ Contusions, typical of adult closed head injuries, are not seen because of the smooth inner surface of the infant skull. The diffuse degeneration of the white matter first defined by Strich $^{3}$ is now commonly known as diffuse axonal injury and is a recognised distinct clinicopathological entity in adult closed head injury. 4 Diffuse axonal injury has not been described in infants under 5 months of age.

We describe diffuse axonal injury in a series of infants 5 months old and younger who had suffered serious closed head injuries. Intracerebral haemorrhages are rarely seen in abused infants, indicating that small blood vessels are not commonly torn at the time of trauma.

\section{Material and methods}

The brains of nine infants (cases 1-9 from Calder et al, 1984) and one additional case (10), all of which had been subject to non-accidental injury and had died of head injury, were studied. The amount of trauma to which the infants had been subjected was difficult to quantify. In four cases $(3,6,8$, and 9$)$ it was severe and in case 10 the final injury was the most important. The brains were fixed and processed, as previously described. $^{2}$ In addition to the staining methods previously described, $10 \mu \mathrm{m}$ sections were stained with the Naoumenko and Feigin, ${ }^{5}$ Rager, Lausmann, and Gallyas, ${ }^{6}$ Loots et $l^{7}$ and Pearson and $\mathrm{O}^{\prime} \mathrm{Neill}^{8}$ silver methods for axons.

Accepted for publication 11 August 1986

\section{Results}

Diffuse axonal inury was not seen with the Pearson and O'Neill, Rager, or Loots silver methods, but diffuse axonal injury was seen in the white matter of both hemispheres and in the corpus callosum of six cases but not in the brain stem with Naoumenko and Feigin's silver method (table). It was characterised by swellings along the axons, increasing their diameter to two or three times the diameter of the parent axon (figs 1-3), and several of these swellings were on the end of an axon giving the appearance of retraction balls (fig 4). In case 8 the axons were severely disrupted, and tuberculosities and retraction balls were not evident. This infant also had a prominent astrocytic reaction, which was shown by immunocytochemistry, using antiserum to glial fibrillary acidic protein (GFAP), suggesting that severe damage had occurred early in the course of the abuse. The axons at the edges of the contusional tears showed a similar degeneration to that described in case 8 . The diffuse axonal injury occurred more commonly in the cases with skull fracture and contusional tears. Large intracerebral haematomata were not present. In case 10 small intracerebral haemorrhages were observed in the superficial white matter of the occipital lobe. The only other recent or old haemorrhages were seen in relation to contusional tears.

\section{Discussion}

Retraction balls and reactive axonal swellings in infants who had suffered a- closed head injury were identified, using the Naoumenko and Feigin silver method. Diffuse axonal injury may occur in the ab- 
Details of 10 cases studied, showing presence of contusional tears, diffuse axonal injury, associated fractures, and extracranial trauma

\begin{tabular}{|c|c|c|c|c|c|c|c|}
\hline Case & $\begin{array}{l}\text { Age } \\
\text { (days) }\end{array}$ & $\operatorname{Sex}$ & $\begin{array}{l}\text { Contusional } \\
\text { tears }\end{array}$ & $\begin{array}{l}\text { Diffuse axonal } \\
\text { injury }\end{array}$ & Skull fracture & $\begin{array}{l}\text { Subdural } \\
\text { haematomas }\end{array}$ & Comment \\
\hline 1 & 12 & $\mathbf{M}$ & + & + & No & Bilateral & $\begin{array}{l}\text { Subretinal haemorrhage, no other } \\
\text { fractures }\end{array}$ \\
\hline 2 & 14 & $\mathbf{M}$ & + & \multirow{3}{*}{\multicolumn{2}{|c|}{$\begin{array}{l}\text { Limited material only available } \\
+\quad \text { Right parietal } \\
+ \\
\text { Limited material only available }\end{array}$}} & & No detailed report available \\
\hline 3 & 17 & $\mathbf{M}$ & $t$ & & & Bilateral, small & Multiple fractures of long bones \\
\hline 4 & 28 & $\mathbf{M}$ & + & & & & No detailed report available \\
\hline 5 & 42 & $\mathbf{F}$ & - & - & No & Bilateral, small & No trauma to the rest of the body \\
\hline 6 & 49 & $\mathbf{M}$ & + & + & Right parietal & Small & Fractured ribs and right femur \\
\hline 7 & 63 & $\mathbf{M}$ & + & + & Right parietal & Bilateral & Multiple fractures of long bones \\
\hline 8 & 84 & $\mathbf{M}$ & + & + & Right parietal & Bilateral & Multiple bruises \\
\hline 9 & 91 & $\mathbf{M}$ & - & - & No & Small, bilateral & $\begin{array}{l}\text { Forehead bruises, extensive gliosis } \\
\text { of brain, multiple rib fractures of } \\
\text { varying ages }\end{array}$ \\
\hline 10 & 140 & $\mathbf{F}$ & - & + & Vault & Bilateral, $\mathbf{L}>\mathbf{R}$ & $\begin{array}{l}\text { Right subdural older than left, old } \\
\text { and recent retinal haemorrhage }\end{array}$ \\
\hline
\end{tabular}

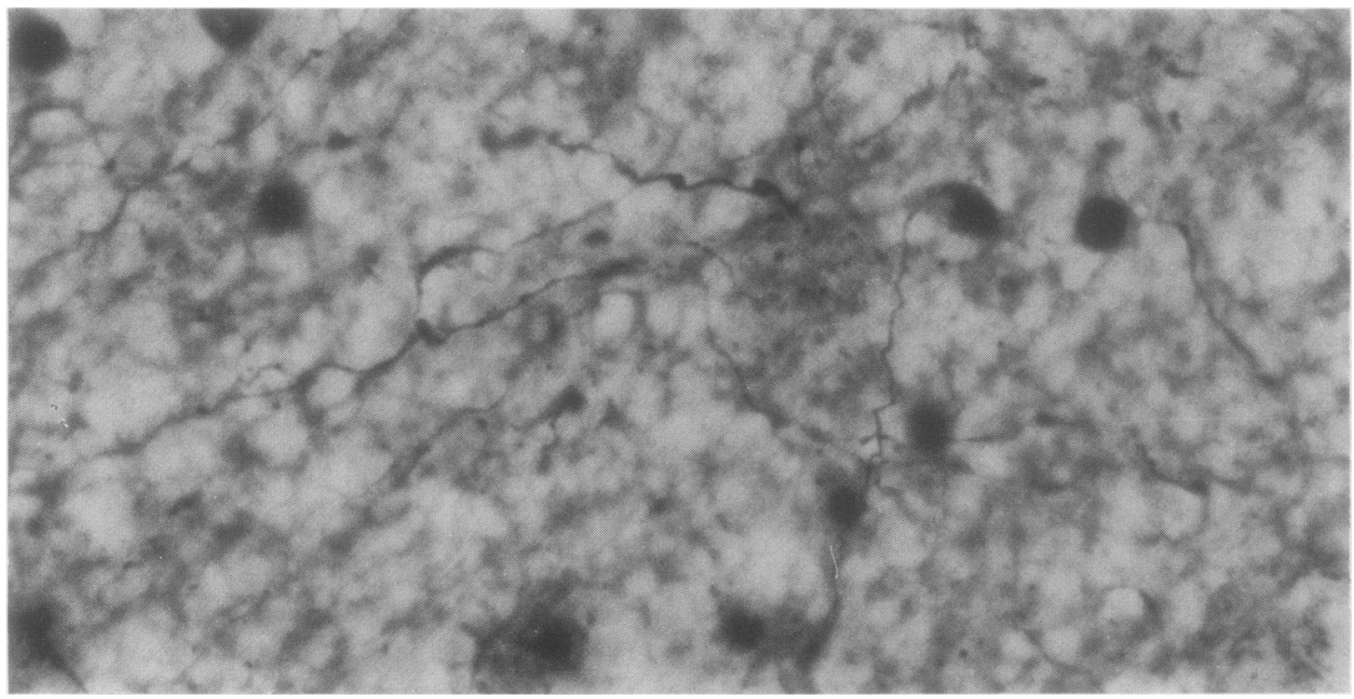

Fig 1 Photomicrograph of white matter from case 3 showing numerous sinusoidal fibres with focal swellings. (Naoumenko and Feigin method.) $\times 200$.

sence of skull fracture or contusional tears, emphasising the importance of microscopic examination of the brain in suspected cases of child abuse. Previous studies of infant brains used Bodian, ${ }^{1}$ Glees and Marsland, and modified Palmgren methods. ${ }^{2}$ These and the Loots, Rager $e t$ al, and Pearson and O'Neill methods $^{6-8}$ used in this study yielded negative results. All these methods, while often routinely used, are insensitive or unreliable when used on immature tissue. Naoumenko and Feigin's method utilises a simple silver solution in saline buffered to $\mathrm{pH} 7.6$ with borate, followed by a simple physical development.
Despite a lengthy impregnation of 24 hours the method was simple and reproducible in our hands and moreover, meant that the finest of neonate axons could be impregnated.

In experimental studies in cats axonal injuries seen as reactive axonal swellings were described on the third to fourth day after trauma. ${ }^{9}$ They were seen to be the sites of accumulation of organelles, neurofilaments, and microtubules, and subsequently there was either separation of the axon or regeneration. We postulate that after separation degeneration of these swellings forms retraction balls over the next 10 days. 


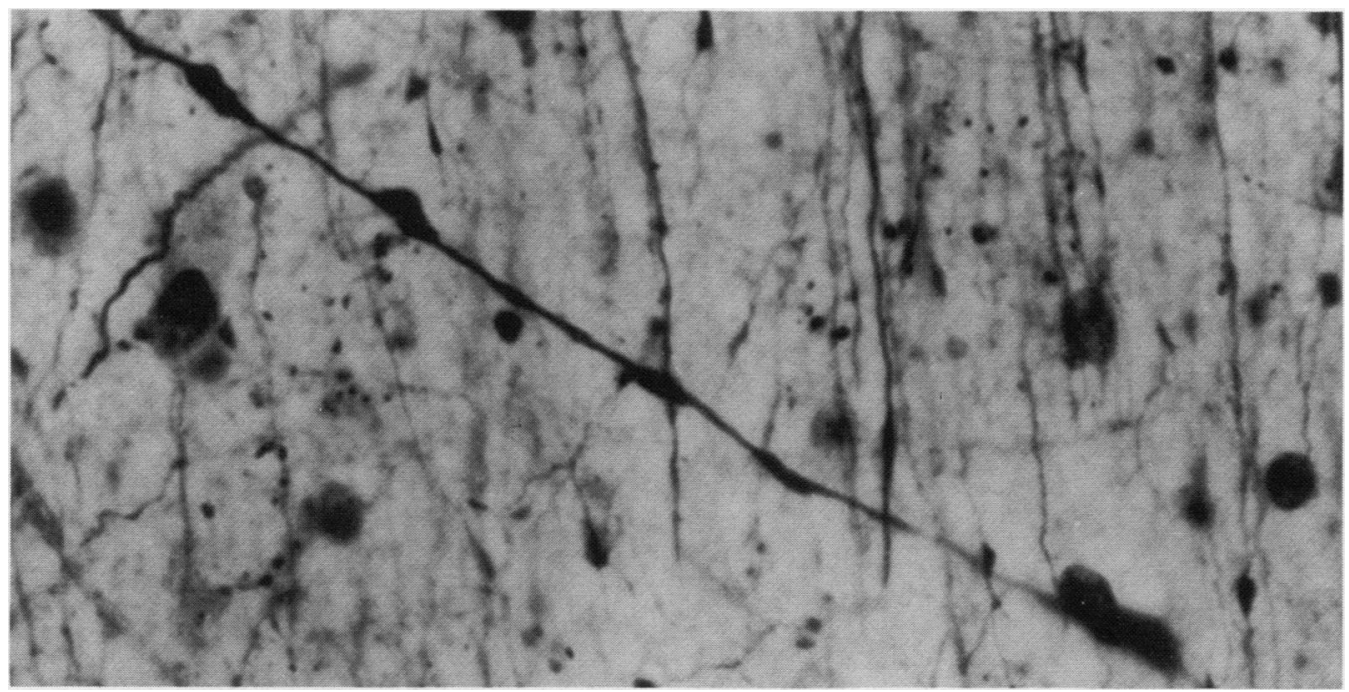

Fig 2 Photomicrograph of fibre from case 1 showing numerous swellings. (Naoumenko and Feigin method.) $\times 250$.

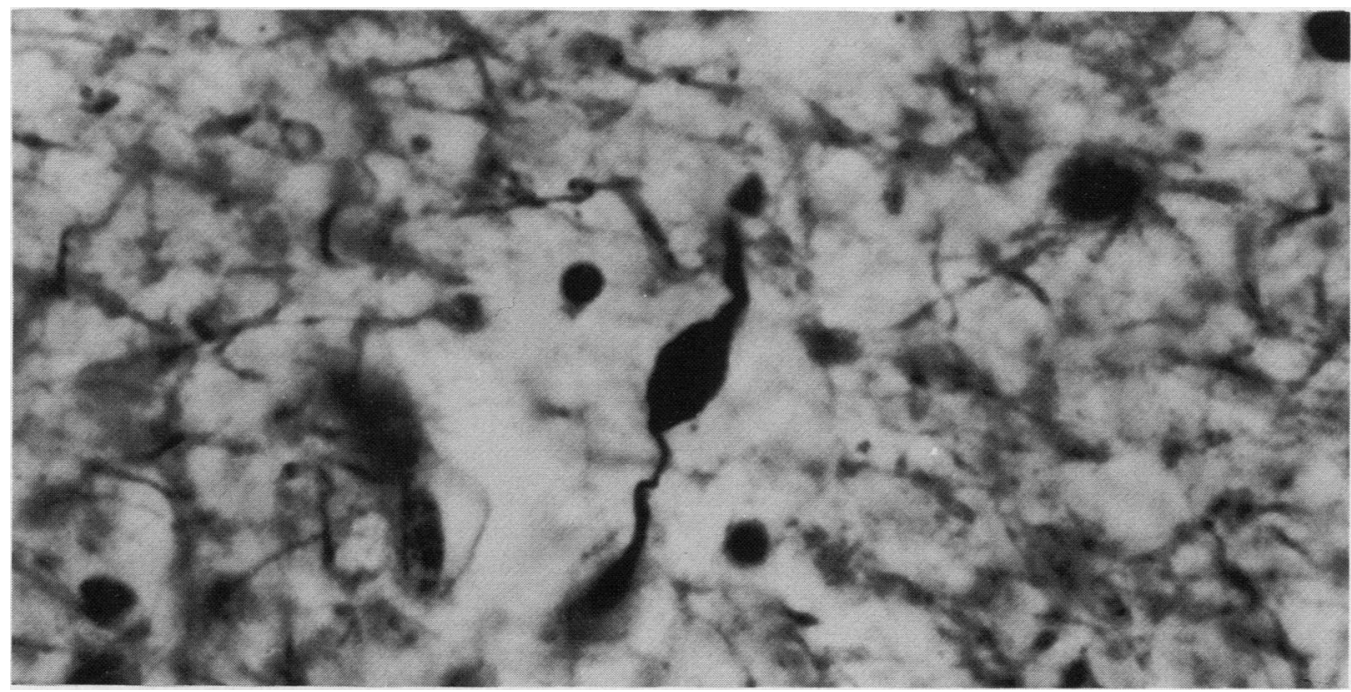

Fig 3 Photomicrograph of particularly large swelling with narrowing of fibre on one side from case 10. (Naoumenko and Feigin method.) $\times 250$.

There was no diffuse axonal injury in two of our cases in which fracture or contusional tears had not occurred. In both these cases the axons were well impregnated.

In adult human head injury diffuse axonal injurysinusoidal enlargement of axons-may be seen two hours after trauma. ${ }^{10}$ In the neonate, however, this observation may not apply as the axons are considerably smaller in diameter, not fully myelinated, and moreover, vary in diameter within tracts. It is therefore difficult to appreciate any enlargement of individual fibres, unless it is expressed as discrete swelling, and the lesions we have described probably take some time to develop; a matter of several hours to one or two days.

Controlled angular acceleration of the head of subhuman primates through $60^{\circ}$ in the sagittal plane leads to acute subdural haematomata. ${ }^{11}$ Slower accel- 


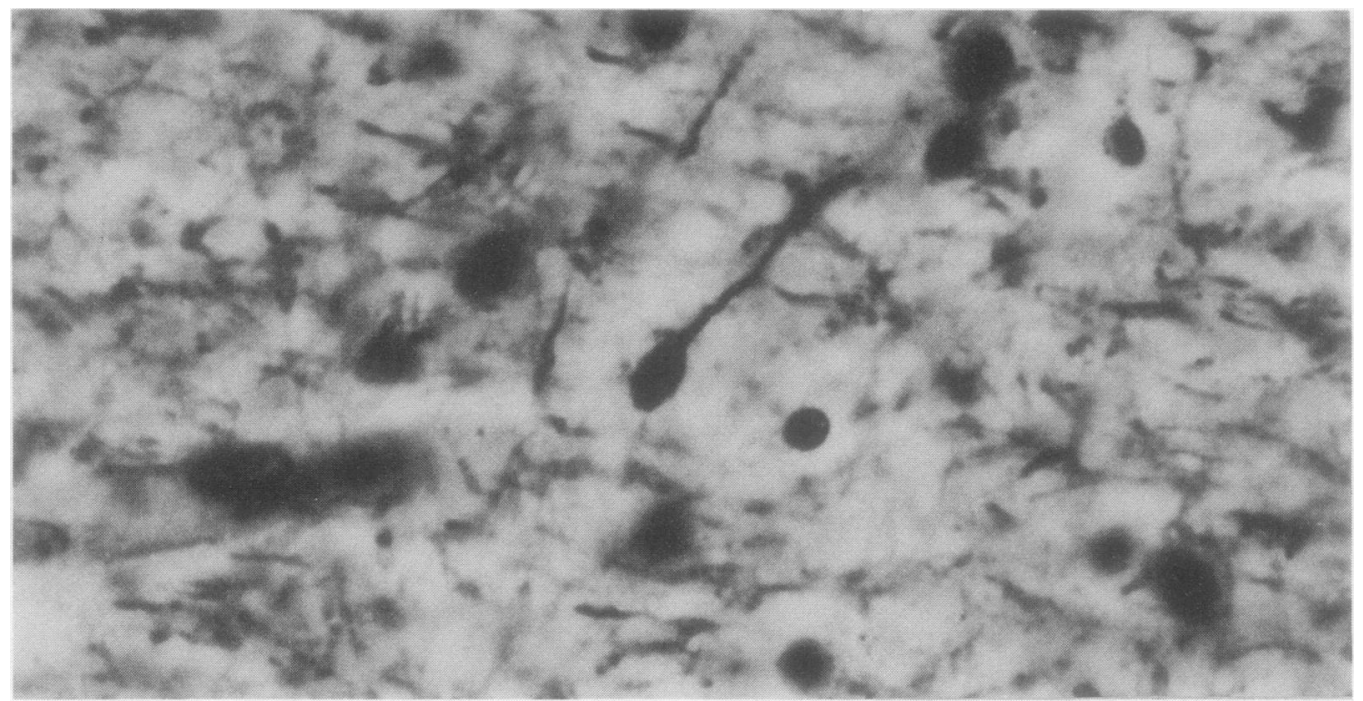

Fig 4 Photomicrograph of swelling on end of fibre resembling retraction ball from case 10 (Naoumenko and Feigin method.) $\times 250$.

eration produces selective damage to axons, particularly if it is lateral, left to right. ${ }^{12}$ In our series all infants, for whom detailed notes were available, had bilateral subdural haematomata. These are common findings in child abuse and reflect the "whiplash shaken injury syndrome", ${ }^{13}$ where the head is accelerated in a sagittal plane.

The presence of skull fractures, diffuse axonal injury, and subdural haemorrhage suggest that abused children are subject to several forms of injury, direct trauma to the skull causing fractures; brain acceleration over a short arc producing subdural haematoma; and slower acceleration in shaking where axons are damaged. This inertial effect may also produce acute subdural haemorrhage as the subdural veins are sensitive to shearing forces. Diffuse axonal injury was not seen in the brain stem. In the diffuse axonal injury described in adults ${ }^{3}$ axonal discontinuities are typically seen in the dorsolateral quadrant of the brain stem. The absence of such lesions in our cases was striking.

In all cases in which contusional tears had occurred diffuse axonal injury was evident. Thus the presence of a contusional tear was focal evidence of more diffuse damage. The experimental studies of axonal damage to subhuman primates, using angular acceleration, suggest that there is a slower component of the acceleration which produces the diffuse axonal injury, ${ }^{9}$ but it is impossible to identify the varieties of trauma used in the cases in our study. The cases in this study were obtained from forensic investigations in which because of the very nature of the implied "baby battering" the clinical history was not medically obtained nor reliably assessed in any of the cases. What is evident, however, is that the injuries were sustained in a totally different manner to those of adult diffuse axonal injury. In adults road traffic accio dents are the single largest cause of diffuse axonak injury, ${ }^{3}$ whereas in our study of infants the injuries were presumed to be derived from shaking, blows, or contact with hard surfaces as a result of abuse.

In many cases of abuse the severity of the assault varies and the last fatal attack is usually the severest. If a child had many episodes of abuse, however, as in case 8 where the child was allegedly repeatedly dropped head first onto a tiled floor, all episodes may produce diffuse axonal injury, and with long survival the pathology of diffuse axonal injury will be at an advanced stage and show degeneration similar to that seen in the long survival cases of adults. ${ }^{14}$ In children less than 5 months of age myelination is at an early stage, and it may be that the axons are less cushioned and more vulnerable to injury than those of adults.

The presence of axonal swellings and retraction balls is evidence of recent injury that has been sustained from three to four days to a few weeks before death. Their presence may support and help to date the injury and may thus provide clinicopathological evidence to elicit the true nature of the injury. The presence of retraction balls at several stages of development will confirm the recurrent injury typically suffered by many battered babies. It is possible that the low IQ observed in many battered infants ${ }^{15}$ may be due to the cumulative effect of diffuse axonal injury produced by. recurrent injury.

Despite our observation of several small focal acute 
haemorrhages in the superficial white matter of the occipital lobe in case 8 large haematomata were absent in this series and in others, ${ }^{12}$ except in relation to the contusional tears. ${ }^{12}$ This is in contrast to the injuries seen in adults with diffuse axonal injury. ${ }^{16}$ In children subjected to recurrent non-accidental injury it is evidently possible to produce diffuse axonal injury without tearing blood vessels. In case 8 the absence of cellular response, including iron laden macrophages in relation to the focal haemorrhages, indicates that these haemorrhages occurred shortly before death and were a terminal anoxic episode. The anatomical site of haemorrhages in relation to the contusional tears is the same as those described in adults as "gliding contusions". They are the site of maximal shearing force $^{17}$ during the injury.

\section{References}

1 Lindenberg R, Freytag E. Morphology of brain lesions from blunt trauma in early infancy. Archives of Pathology 1969;87:298-305.

2 Calder IM, Hill I, Scholtz CL. Primary brain trauma in nonaccidental injury. J Clin Pathol 1984;37:1095-100.

3 Strich SJ. Diffuse degeneration of the cerebral white matter in severe dementia following head injury. $J$ Neurol Neurosurg Psychiatry 1956;19:163-85.

4 Adams JH, Graham DI, Murray LS, Scott G. Diffuse axonal injury due to non missile head injury in humans: an analysis of 45 cases. Ann Neurol 1982;12:557-63.

5 Naoumenko J, Feigin I. A stable silver solution for axon staining in paraffin sections. J Neuropathol Exp Neurol 1967;26:669-73.

6 Rager G, Lausmann S, Gallyas F. An improved silver stain for developing nervous tissue. Stain Technol 1979;54:193-200.

7 Loots GP, Loots JM, Brown JM, Schoeman JL. A rapid silver impregnation method for nervous tissue: a modified protargolperoxide technic. Stain Technol 1979;54:97-100.

8 Pearson AA, O'Neill SL. Silver-gelatin method for staining nerve fibres. Anat Rec 1946;95:297-301.

9 Povlishock JT, Becker DP. Fate of reactive axonal swellings induced by head injury. Lab Invest 1985;52:540-52.

10 Scholtz CL, Chan KK. White matter damage following acute head injury. J Neuropathol Appl Neurol 1985;11:319.

11 Adams JH, Graham DI, Gennarelli TA. Acceleration induced head injury in the monkey II neuropathy. Acta Neuropathol 1981;Suppl VII:26-8.

12 Gennarelli TA, Thibault LE, Thompson C, Adams JH, Graham DI. Diffuse axonal injury produced by angular acceleration in the sub-human primate. Ann Neurol 1984;12:564-74.

13 Caffey J. The whiplash syndrome. Pediatrics 1979;4:396-403.

14 Adams JH, Mitchell DE, Graham DI, Doyle D. Diffuse brain damage of immediate impact type. Brain 1977;100:489-502.

15 Silver E, Gregg GS. Developmental characteristics of abused children. Pediatrics 1967;40:596-602.

16 Adams JH, Doyle D, Graham DI, Lawrence AE. McLellan DR. Deep intracerebral (basal ganglia) haematomata in fatal nonmissile head injury in man. $J$ Neurol Neurosurg Psychiatry 1986;49:1039-43.

17 Adams JH, Doyle D, Graham DI. Lawrence AE, McLellan DR. Gliding contusions in non-missile head injuries in man. Arch Pathol Lab Med 1986;110:485-8.

Requests for reprints to: Dr CL Scholtz, Department of Morbid Anatomy, The London Hospital, London E1 1BB, England. 